\title{
Echocardiographic assessment of left atrial morphology and function to predict maintenance of sinus rhythm after electrical cardioversion in patients with non-valvular persistent atrial fibrillation and normal function or mild dysfunction of left ventricle
}

\author{
Paweł Wałek ${ }^{1}$, Janusz Sielski ${ }^{1,3}$, Katarzyna Starzyk ${ }^{2}$, Iwona Gorczyca ${ }^{2}$, \\ Joanna Roskal-Wałek ${ }^{3}$, Beata Wożakowska-Kapłon ${ }^{2,3}$ \\ ${ }^{1}$ Intensive Cardiac Care Unit, Swietokrzyskie Cardiology Center, Kielce, Poland \\ ${ }^{2}$ Department of Cardiology and Electrotherapy, Swietokrzyskie Cardiology Center, Kielce, Poland \\ ${ }^{3}$ Faculty of Medicine and Health Sciences, The Jan Kochanowski University, Kielce, Poland
}

\begin{abstract}
Background: The aim of this study was to assess whether echocardiographic measurements of left atrial (LA) morphology and function could predict sinus rhythm maintenance after electrical cardioversion among patients with atrial fibrillation $(A F)$ and normal function or mild dysfunction of the left ventricle $(L V)$.

Methods: One hundred seventeen patients with persistent $A F$ who underwent successful electrical cardioversion were prospectively enrolled. Echocardiography was performed one day subsequent to successful cardioversion. Patients were followed up clinically and electrocardiographically at 1, 6, and 12 months. At 12 months, 61 (52\%) patients had maintained sinus rhythm (SR).

Results: Compared to patients who maintained $S R$, those with $A F$ recurrence had larger $L A s$, worse $L A$ systolic function, and increased LV filling pressure. On multivariate stepwise logistic regression, $E / A$ ratios (odds ratio [OR] 0.550, 95\% confidence interval [CI] 0.341-0.886; $p=0.014$ ) and E/e' ratios (OR 0.871, 95\% CI 0.771-0.985; $p=0.027$ ) were significant predictors of $A F$ recurrence. On receiver operator characteristic curve analysis of $A F$ recurrence at 12 months, the area under curve for both $E / A$ and E/e' ratios were 0.726. With an E/A cutoff of 2.2, the sensitivity for predicting $A F$ recurrence at 12 months was $72 \%$, and specificity was $73 \%$. With an E/e' cutoff of 9.17, the sensitivity for predicting $A F$ recurrence at 12 months was $72 \%$, and specificity was $74 \%$.

Conclusions: Left ventricular filling pressure assessed with $E / A$ and $E / e^{\prime}$ ratios predict $A F$ recurrence after electrical cardioversions among patients with $A F$ and normal function of $L V$. (Cardiol J 2020; 27, 3: 246-253)
\end{abstract}

Key words: atrial fibrillation, direct current cardioversion, diastolic dysfunction

\section{Introduction}

Atrial fibrillation (AF) is the most common arrhythmia, and it is caused by structural, mechanical, and electrical remodeling of the atria, including atrial enlargement, fibrosis, and dysfunction of ion channels [1-3]. Management of AF is aimed at restoration and maintenance of sinus rhythm (SR) or control of the ventricular rate [4]. In the Euro Heart Survey, the effectiveness of cardioversion

Address for correspondence: Paweł Wałek, MD, Intensive Cardiac Care Unit, Świętokrzyskie Cardiology Center, ul. Grunwaldzka 45, 25-736 Kielce, Poland, tel: +48 41 3671493, fax: +48 41 3671510, e-mail: pawel.walek@o2.pl 
was about $75-88 \%$, depending on the cardioversion method and patient characteristics. In the same registry, about $70 \%$ of patients maintained SR for 12 months [5]. AF recurs in many patients after successful cardioversion, and this recurrence is associated with different clinical, electrocardiographic, echocardiographic, imaging, and laboratory factors [2, 6-9]. Risk factors for recurrence of AF can help select patients in whom cardioversion can restore SR in the long-term. Moreover, patients with a very high risk of AF recurrence could avoid the risk of cardioversion. Under investigation, in this study, was whether assessing left atrial (LA) morphology and function by echocardiography could help predict the recurrence of AF after electrical cardioversion.

\section{Methods}

The study protocol was approved by the local ethics committee. This prospective study enrolled 117 patients with persistent AF who underwent direct current cardioversion between August 2015 and April 2017 on a cardiology ward. The inclusion criteria were as follows: symptomatic persistent $\mathrm{AF}$ for $\geq 7$ days, ejection fraction $>40 \%$, and effective anticoagulation with warfarin, acenocumarol, or novel oral anticoagulants (dabigatran, rivaroxaban, apixaban) for $\geq 3$ weeks prior to cardioversion. The exclusion criteria were as follows: age $<18$ years, no consent to participate in the study, no consent for cardioversion, low quality of echocardiographic images, moderate or severe valve regurgitation or stenosis, valvular prosthesis, presence of thrombus in the left atrial appendage (LAA), acute decompensation of heart failure, acute myocardial infarction, previous pulmonary vein isolation, dysthyroidism, anemia (hemoglobin $<6.9 \mathrm{mmol} / \mathrm{L}$ ), and cancer.

Patients were followed up at 1,6 , and 12 months to check for maintenance of SR (electrocardiogram on each visit and 24-h Holter monitoring at 1 and 12 months). Patients were asked to report to the cardiology department if they felt palpitations or thought that $\mathrm{AF}$ had recurred.

Clinical data were obtained on the day of cardioversion and included age, sex, body mass index (BMI), body surface area (BSA, calculated with the Gehan and George formula), glomerular filtration rate (GFR, calculated with the Cockroft-Gault formula), hypertension, diabetes mellitus, dyslipidemia, smoking status, history of coronary artery disease, European Heart Rhythm Association (EHRA) score, dysthyroidism, obstructive pulmonary disease, renal disease, and history of stroke or transient ischemic attack. Coronary artery disease was diagnosed when patients had a history of myocardial infarction, percutaneous coronary intervention, or coronary artery by-pass grafting. Data regarding AF duration and duration of the current AF episode is not taken into account because of the high percentage of patients who were unable to ascertain the onset of arrhythmias. $\mathrm{CHA}_{2} \mathrm{DS}_{2}$-VASc and HAS-BLED scores were recorded according to the current European guidelines on $\mathrm{AF}$ treatment [4].

All cardioversions were performed with anaesthesiologic assistance under general sedation. All cardioversions were performed with a biphasic defibrillator (150-300 J). If the first shock was ineffective, another attempt was performed with a higher energy (by $100 \mathrm{~J}$ ). The success of cardioversion was defined as SR maintenance for $\geq 24$ h. Patients with SR received anticoagulants, up-stream therapy, or antiarrhythmic drugs by clinical judgment. Antiarrhythmic drugs, like amiodarone and propafenone, were prescribed by a physician blinded to echocardiography results.

Echocardiography was performed on the day after successful cardioversion, during SR. One experienced investigator performed transthoracic echocardiography with the Vivid S6 device (General Electric Medical Systems, Horten, Norway) and the M4S RS transducer, according to current guidelines $[10,11]$. Standard M-mode and Doppler images and 2-dimentional cine loops were obtained in the parasternal long and short axis views and apical 2-, 3-, and 4-chamber views. Echocardiographic data were stored and analysed offline with the EchoPAC PC software (GE Medical Systems). The maximal end-systolic volume of left atrium (LAV) and minimal end-diastolic volume (LAEDV) were measured by the Simpson method from apical 4- and 2-chamber views. Maximum volume of LA (LAV) was measured at the end of systole, on the frame just before mitral valve opening, by tracing the inner border of the atrium and avoiding the area under the valve annulus, appendage, and pulmonary veins. LAV was indexed to body surface area (BSA, LAVI). Minimum volume of LA was measured at the end of ventricular diastole on the frame of the mitral valve closure, and was indexed to BSA (LAEDVI). LA emptying fraction (LA EF) was calculated with the following formula: (LA maximum volume - LA minimum volume)/LA maximum volume $\times 100 \%$. Left ventricular (LV) volume and ejection fraction (LVEF) were measured according to the Simpson formula. The area 
of right atrium at systole (RAAs) was measured in an apical 4-chamber view at the end of the systole, and the right atrium area at the diastole (RAAd) was measured at the end of the diastole on the frame with the tricuspid valve closure. Blood flow velocities were measured by transmitral pulsed wave Doppler (PWD) from the apical 4-chamber view, with a $2-\mathrm{mm}$ sample volume placed between the tips of the mitral leaflets. Mitral annulus motion was measured by tissue Doppler imaging (TDI) in an apical 4-chamber view with a 5 -mm sample volume at the lateral and septal basal regions. Means of waves s', e', and a' were calculated as averages from the septal and lateral measurements.

\section{Statistical analysis}

Results are presented as means \pm standard deviations (SD). Categorical variables are presented as counts and percentages. Normally distributed variables were compared with the Student t-test, and non-normally distributed variables were compared with the Mann-Whitney test or $\chi^{2}$ test.

Predictors of SR maintenance were analyzed with univariate logistic regression. To identify independent predictors of AF recurrence, a multivariable model that included independent variables with $\mathrm{p}$ value of $<0.1$ found in univariate analysis and adjusted by important cofactors that might have an influence on outcomes was performed. The stepwise inclusion was set at $\mathrm{p}<0.05$ and exclusion at $\mathrm{p}>0.1$. Receiver-operated characteristic (ROC) curves for predicting SR maintenance at 1, 6, and 12 months were calculated for selected echocardiographic variables. Optimal cutoffs were calculated based on the Youden statistic, and areas under the curve (AUC) were compared with the DeLong test with the AUC that indicated no diagnostic values (0.5). Significance was set at $p<0.05$. Statistical analyses were performed with MedCalc Statistical Software version 18.6 (MedCalc Software bvba, Ostend, Belgium).

\section{Results}

One hundred seventeen patients who underwent successful electrical cardioversion were included in the study. Of these patients, 56 (47.8\%) maintained SR at 12 months. Compared with patients with $\mathrm{AF}$ recurrence, patients who maintained SR at 12 months were younger $(p=0.027)$, were more often male $(\mathrm{p}=0.024)$, had diabetes mellitus more often $(\mathrm{p}=0.047)$, had higher GFR values $(\mathrm{p}=0.043)$, used beta-blockers more often before and after cardioversion ( $\leq 0.030)$, and used diuretics less often before and after cardioversion $(\mathrm{p} \leq 0.010)$. There were no other significant differences in baseline characteristics between patients who maintained SR over 12 months and the remaining patients (Table 1 ).

Nearly all patients had LA enlargement, with a mean LAVI of $49.7 \pm 11.4 \mathrm{~mL} / \mathrm{m}^{2}$ and low or moderate LA enlargement in the antero-posterior dimension $(44.5 \pm 4.7 \mathrm{~mm})$. Compared with patients with $\mathrm{AF}$ recurrence, patients who maintained SR at 12 months had significantly lower values of LAVI $(\mathrm{p}=0.001)$ and LAEDVI $(\mathrm{p}<0.001)$.

Compared with patients with AF recurrence, patients who maintained SR at 12 months had a significantly higher LA EF $(\mathrm{p}<0.001)$, atrial filling wave A ( $\mathrm{p}=0.033)$, and late diastolic mitral annular velocity (wave a', $\mathrm{p}=0.041$ ).

Compared with patients with AF recurrence, patients who maintained SR at 12 months had significantly lower $\mathrm{E} / \mathrm{e}^{\prime}$ ratios ( $\mathrm{p}<0.001$ ), $\mathrm{E} / \mathrm{A}$ ratios $(\mathrm{p}<0.001$ ), and early filling velocities (wave $\mathrm{E}$, $\mathrm{p}<0.001)$, and they had significantly higher early diastolic mitral annular velocities (wave e, $\mathrm{p}=0.008$ ) and deceleration times of wave $\mathrm{E}$ (DT, $\mathrm{p}=0.003)$.

Patients with AF recurrence and patients who maintained SR at 12 months did not differ significantly with respect to LV function. However, patients who maintained SR at 12 months tended to have higher values of mitral annular peak systolic velocity (wave s', $\mathrm{p}=0.051$ ). Table 2 presents values for all echocardiographic variables.

On univariate logistic regression, the following echocardiographic variables were significant predictors of SR maintenance at 12 months: LAVI, LAEDVI, LA EF, waves s', e', and E, E/e' and E/A ratios, and DT (Table 3). On multivariate stepwise, forward, and backward logistic regression, only $\mathrm{E} / \mathrm{e}$ ' and $\mathrm{E} / \mathrm{A}$ ratios remained significant predictors of SR maintenance. In ROC curve analysis, both $\mathrm{E} / \mathrm{e}$ ' and $\mathrm{E} / \mathrm{A}$ ratios had a similar value for predicting SR maintenance at 1,6 , and 12 months, with AUCs of about 0.7 and sensitivity, specificity, and predictive values of about 70-75\% (Figs. 1 and 2, Table 4). In ROC curve analysis of E/e' and E/A for predicting SR maintenance at 12 months of observation AUC of E/e' was 0,726 (95\% confidence interval [CI] 0.630-0.822) and $\mathrm{E} / \mathrm{A}$ was $0.726(95 \%$ CI 0.632-0.821).

\section{Discussion}

In this study, it was shown that LV filling pressure and atrial enlargement were significant predic- 
Table 1. Baseline characteristics.

\begin{tabular}{|c|c|c|c|c|}
\hline & $\begin{array}{l}\text { Study population; } \\
\qquad \mathrm{n}=117\end{array}$ & $\begin{array}{l}\text { SR maintenance; } \\
\quad n=61(52 \%)\end{array}$ & $\begin{array}{l}\text { No SR maintenance; } \\
\quad n=56(47.8 \%)\end{array}$ & $\mathbf{P}$ \\
\hline Age [years] & $65 \pm 10.4$ & $62.984 \pm 11.5593$ & $67.196 \pm 8.6811$ & 0.027 \\
\hline Age $<65$ years & $48(41 \%)$ & $29(47.5 \%)$ & $19(33.9 \%)$ & 0.137 \\
\hline Age $65-74$ years & $51(43.6 \%)$ & $24(39.3 \%)$ & $27(48.2 \%)$ & 0.336 \\
\hline Age $\geq 75$ years & $18(15.4 \%)$ & $9(14.8 \%)$ & $9(16.1 \%)$ & 0.844 \\
\hline Male & $73(62.4 \%)$ & $44(72.1 \%)$ & $29(51.8 \%)$ & 0.024 \\
\hline Body mass index $\left[\mathrm{kg} / \mathrm{m}^{2}\right]$ & $30.9 \pm 7.7$ & $31.6 \pm 9.4$ & $30.1 \pm 5.3$ & 0.324 \\
\hline Hypertension & $98(83.8 \%)$ & $50(82 \%)$ & $48(85.7 \%)$ & 0.585 \\
\hline Diabetes mellitus & $22(18.8 \%)$ & $13(21.3 \%)$ & $9(16.1 \%)$ & 0.047 \\
\hline Coronary artery disease & $18(15.5 \%)$ & $10(16.4 \%)$ & $8(14.5 \%)$ & 0.785 \\
\hline EHRA III-IV & $38(32.5 \%)$ & $21(34.4 \%)$ & $17(30.4 \%)$ & 0.640 \\
\hline Stroke/TIA & $10(8.5 \%)$ & $5(8.2 \%)$ & $5(8.9 \%)$ & 0.888 \\
\hline Vascular disease & $13(11.1 \%)$ & $8(13.1 \%)$ & $5(8.9 \%)$ & 0.474 \\
\hline $\mathrm{CHA}_{2} \mathrm{DS}_{2}$-VASC & $2.7 \pm 1.5$ & $2.6 \pm 1.5$ & $2.8 \pm 1.6$ & 0.230 \\
\hline $\mathrm{CHA}_{2} \mathrm{DS}_{2}-\mathrm{VASC}=0$ & $7(6 \%)$ & $3(4.9 \%)$ & $4(7.1 \%)$ & 0.614 \\
\hline $\mathrm{CHA}_{2} \mathrm{DS}_{2}-\mathrm{VASC}=1$ & $22(18.8 \%)$ & $14(23 \%)$ & $8(14.3 \%)$ & 0.233 \\
\hline $\mathrm{CHA}_{2} \mathrm{DS}_{2}-\mathrm{VASC} \geq 2$ & $88(75.2 \%)$ & $44(72.1 \%)$ & $44(78.6 \%)$ & 0.422 \\
\hline HAS-BLED & $0.7 \pm 0.6$ & $0.8 \pm 0.5$ & $0.9 \pm 0.4$ & 0.566 \\
\hline Smokers & $7(6 \%)$ & $4(6.6 \%)$ & $3(5.4 \%)$ & 0.785 \\
\hline GFR $[\mathrm{mL} / \mathrm{min}]$ & $85.6 \pm 31.1$ & $91 \pm 30$ & $79.6 \pm 31.4$ & 0.043 \\
\hline Beta-blockers pre & $107(92.2 \%)$ & $59(98.3 \%)$ & $48(85.7 \%)$ & 0.012 \\
\hline Amiodarone pre & $13(11.1 \%)$ & $6(9.8 \%)$ & $7(12.5 \%)$ & 0.648 \\
\hline ACEI/ARB pre & $99(84.6 \%)$ & $51(83.6 \%)$ & $48(85.7 \%)$ & 0.753 \\
\hline Statins pre & $74(63.8 \%)$ & $42(70 \%)$ & $32(57.1 \%)$ & 0.152 \\
\hline Diuretics pre & $48(42.1 \%)$ & $18(30.5 \%)$ & $30(54.5 \%)$ & 0.009 \\
\hline $\begin{array}{l}\text { Spironolactone/ } \\
\text { /eplerenone pre }\end{array}$ & $25(22.1 \%)$ & $16(27.1 \%)$ & $9(16.7 \%)$ & 0.183 \\
\hline Beta-blockers post & $91(79.1 \%)$ & $53(86.9 \%)$ & $38(70.4 \%)$ & 0.030 \\
\hline Amiodarone post & $37(32.2 \%)$ & $19(31.1 \%)$ & $18(33.3 \%)$ & 0.803 \\
\hline Propafenone post & $37(32.2 \%)$ & $20(32.8 \%)$ & $17(31.5 \%)$ & 0.882 \\
\hline ACEl/ARB post & $99(84.6 \%)$ & $52(85.2 \%)$ & $47(83.9 \%)$ & 0.844 \\
\hline Statins post & $73(63.5 \%)$ & $40(65.6 \%)$ & $33(61.1 \%)$ & 0.621 \\
\hline Diuretics post & $49(43 \%)$ & $19(31.7 \%)$ & $30(55.6 \%)$ & 0.010 \\
\hline $\begin{array}{l}\text { Spironolactone/ } \\
\text { /eplerenone post }\end{array}$ & $28(25 \%)$ & $17(28.3 \%)$ & $11(21.2 \%)$ & 0.384 \\
\hline
\end{tabular}

ACEI - angiotensin converting enzyme inhibitors; ARB - angiotensin II receptor blockers; EHRA - European Heart Rhythm Association; GFR — glomerular filtration rate; pre — before cardioversion; post — after cardioversion; SR — sinus rhythm; TIA — transient ischemic attack

tors of SR maintenance after electrical cardioversion in patients with AF. Moreover, parameters of LV filling pressure were independent predictors of AF recurrence.

Although electrical cardioversion is effective in most patients with $\mathrm{AF}$, high rates of $\mathrm{AF}$ recurrence are observed regardless of anti-arrhythmic therapy used. The current study investigated the relationship between echocardiographic param- eters and AF recurrence after electrical cardioversion among patients with normal function of $\mathrm{LV}$. Also in the present study, about half of the patients maintained SR over 12 months after a successful electrical cardioversion, which is similar to the figure from the Euro Heart Survey registry (61\%) [5]. A slightly higher rate in the Euro Heart Survey could be because this registry included patients with first detected, paroxysmal, and persistent $\mathrm{AF}$. 
Table 2. Echocardiographic variables.

\begin{tabular}{|c|c|c|c|c|}
\hline & $\begin{array}{l}\text { Study population, } \\
\qquad n=117\end{array}$ & $\begin{array}{l}\text { SR maintenance, } \\
n=61(52 \%)\end{array}$ & $\begin{array}{c}\text { No SR maintenance, } \\
n=56(47.8 \%)\end{array}$ & $\mathbf{P}$ \\
\hline $\mathrm{RV}$ prox $[\mathrm{mm}]$ & $31.2 \pm 3.8$ & $31.7 \pm 4.1$ & $30.6 \pm 3.5$ & 0.224 \\
\hline IVS [mm] & $10.8 \pm 1.8$ & $10.6 \pm 1.7$ & $11.1 \pm 1.8$ & 0.229 \\
\hline LVEDD [mm] & $51.4 \pm 6.5$ & $51.9 \pm 6.6$ & $50.8 \pm 6.4$ & 0.351 \\
\hline LVESD [mm] & $36 \pm 7.8$ & $36.8 \pm 8.2$ & $35.2 \pm 7.4$ & 0.292 \\
\hline LVEDV [mL] & $133.8 \pm 39.4$ & $138.2 \pm 38.6$ & $128.7 \pm 40$ & 0.192 \\
\hline LVESV [mL] & $56.2 \pm 25$ & $58.6 \pm 26.6$ & $53.7 \pm 23.1$ & 0.435 \\
\hline LVSV [mL] & $77.6 \pm 23.2$ & $80.2 \pm 21.5$ & $74.8 \pm 24.8$ & 0.213 \\
\hline $\mathrm{EF}[\%]$ & $59.3 \pm 9.6$ & $59.2 \pm 9.9$ & $59.4 \pm 9.4$ & 0.896 \\
\hline LA AP [mm] & $44.5 \pm 4.7$ & $44 \pm 4.1$ & $44.9 \pm 5.2$ & 0.281 \\
\hline LAVI $\left[\mathrm{mL} / \mathrm{m}^{2}\right]$ & $49.7 \pm 11.4$ & $46.6 \pm 10.4$ & $53.1 \pm 11.5$ & 0.001 \\
\hline LAEDV index $\left[\mathrm{mL} / \mathrm{m}^{2}\right]$ & $32.5 \pm 11.2$ & $28.8 \pm 9.3$ & $36.5 \pm 11.7$ & $<0.001$ \\
\hline LA EF [\%] & $35.9 \pm 10.6$ & $39 \pm 8.4$ & $32.5 \pm 11.7$ & $<0.001$ \\
\hline RAA s $\left[\mathrm{cm}^{2}\right]$ & $22.8 \pm 5$ & $22.5 \pm 5.3$ & $23.1 \pm 4.6$ & 0.517 \\
\hline $\mathrm{RAA} d\left[\mathrm{~cm}^{2}\right]$ & $15.7 \pm 3.9$ & $15.9 \pm 3.9$ & $15.6 \pm 3.9$ & 0.799 \\
\hline $\mathrm{s}^{\prime}$ mean $[\mathrm{cm} / \mathrm{s}]$ & $6.5 \pm 1.8$ & $6.8 \pm 1.9$ & $6.2 \pm 1.6$ & 0.051 \\
\hline $\mathrm{e}^{\prime}$ mean $[\mathrm{cm} / \mathrm{s}]$ & $9.4 \pm 2.3$ & $10 \pm 2.3$ & $8.8 \pm 2.1$ & 0.008 \\
\hline$a^{\prime}$ mean $[\mathrm{cm} / \mathrm{s}]$ & $5.1 \pm 2.2$ & $5.4 \pm 2.1$ & $4.8 \pm 2.2$ & 0.041 \\
\hline $\mathrm{E} / \mathrm{e}^{\prime}$ mean & $10.3 \pm 4$ & $9 \pm 3.5$ & $11.8 \pm 4.1$ & $<0.001$ \\
\hline $\mathrm{E}[\mathrm{m} / \mathrm{s}]$ & $0.9 \pm 0.2$ & $0.9 \pm 0.2$ & $1 \pm 0.2$ & $<0.001$ \\
\hline $\mathrm{A}[\mathrm{m} / \mathrm{s}]$ & $0.4 \pm 0.2$ & $0.5 \pm 0.2$ & $0.4 \pm 0.2$ & 0.033 \\
\hline$E / A$ & $2.4 \pm 1.1$ & $2 \pm 0.8$ & $2.9 \pm 1.3$ & $<0.001$ \\
\hline DT [ms] & $183.4 \pm 42.7$ & $193.9 \pm 42.9$ & $171.7 \pm 39.6$ & 0.003 \\
\hline
\end{tabular}

SR — sinus rhythm; RV prox — right ventricular proximal diameter; IVS — interventricular septum wall thickness; LVEDD — left ventricular end-diastolic diameter; LVESD - left ventricular end-systolic diameter; LVEDV — left ventricular end-diastolic volume; LVESV — left ventricular end-systolic volume; LVSV - left ventricular stroke volume; EF — ejection fraction; LAAP — left atrium anteroposterior diameter; LAVI end-systolic volume of left atrium indexed to body surface area; LAEDV — minimal end-diastolic volume; LA EF — emptying fraction of left atrium; RAA — right atrium area; $d$ - diastolic; $s$ - systolic; DT — deceleration times of wave E

Table 3. Echocardiographic predictors of sinus rhythm maintenance at 12 months.

\begin{tabular}{|c|c|c|c|c|c|c|}
\hline & \multicolumn{3}{|c|}{ Univariate analysis } & \multicolumn{3}{|c|}{ Multivariable stepwise analysis } \\
\hline & OR & $95 \% \mathrm{Cl}$ & $\mathbf{P}$ & OR & $95 \% \mathrm{Cl}$ & $\mathbf{P}$ \\
\hline LAVI $\left[\mathrm{mL} / \mathrm{m}^{2}\right]$ & 0.946 & $0.912-0.982$ & 0.003 & & & \\
\hline LAEDVI $\left[\mathrm{mL} / \mathrm{m}^{2}\right]$ & 0.928 & $0.891-0.968$ & $<0.001$ & & & \\
\hline LA EF [\%] & 1.066 & $1.025-1.109$ & 0.002 & & & \\
\hline $\mathrm{s}^{\prime}$ mean $[\mathrm{cm} / \mathrm{s}]$ & 1.252 & $1.003-1.564$ & 0.047 & & & \\
\hline $\mathrm{e}^{\prime}$ mean $[\mathrm{cm} / \mathrm{s}]$ & 1.258 & $1.057-1.497$ & 0.010 & & & \\
\hline$E[\mathrm{~m} / \mathrm{s}]$ & 0.056 & $0.008-0.389$ & 0.004 & & & \\
\hline $\mathrm{A}[\mathrm{m} / \mathrm{s}]$ & 10.402 & $0.995-108.754$ & 0.051 & & & \\
\hline E/e' mean & 0.815 & $0.724-0.916$ & 0.001 & 0.871 & $0.771-0.985$ & 0.027 \\
\hline$E / A$ & 0.421 & $0.266-0.667$ & $<0.001$ & 0.550 & $0.341-0.886$ & 0.014 \\
\hline DT [ms] & 1.014 & $1.004-1.024$ & 0.007 & & & \\
\hline
\end{tabular}

$\mathrm{Cl}$ - confidence interval; OR — odds ratio; LAVI — end-systolic volume of left atrium indexed to body surface area; LAEDVI — minimal end-diastolic volume indexed to body surface area; LA EF — left atrium emptying fraction; DT — deceleration times of wave E 


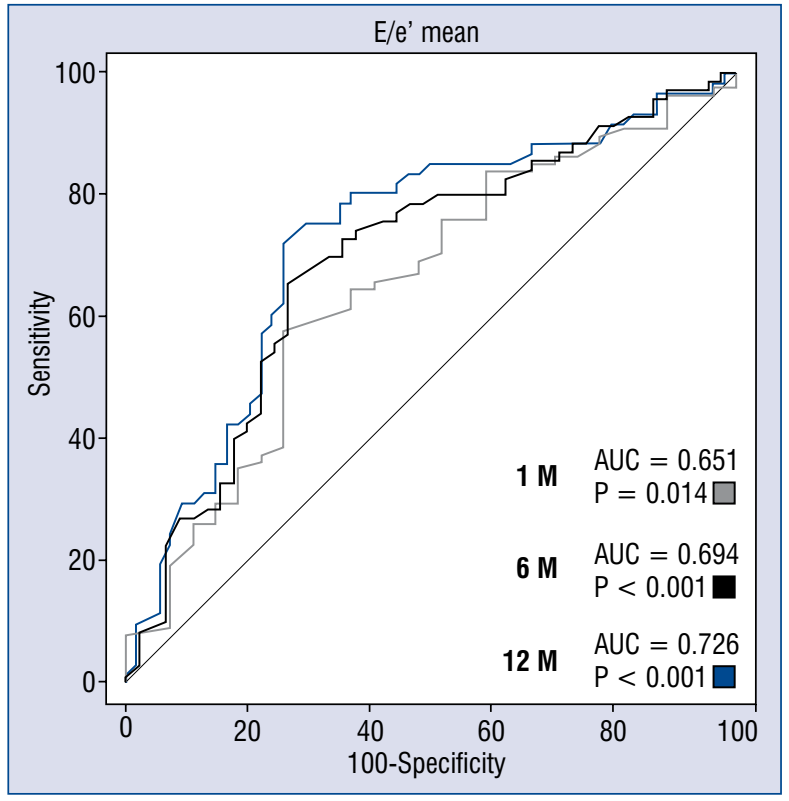

Figure 1. Prediction of sinus rhythm maintenance at 1, 6, and 12 months. Receiver operating characteristic curves for $E / e^{\prime}$ ratios. $P$ values for AUC comparisons with no effect (AUC $=0.5$, DeLong test); AUC - area under the curve; $\mathrm{M}-$ month.

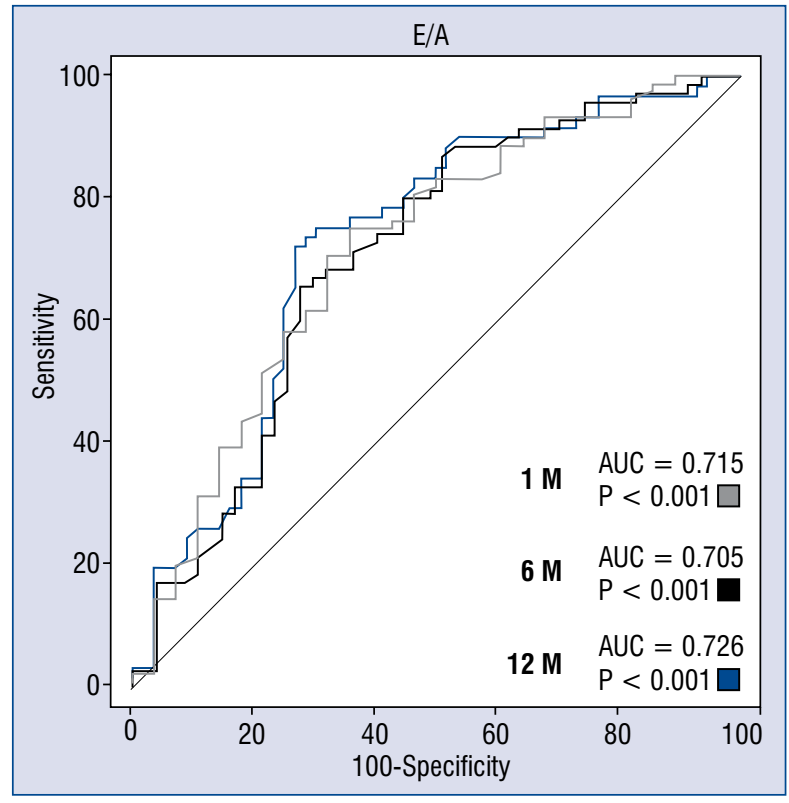

Figure 2. Prediction of sinus rhythm maintenance at 1,6 , and 12 months. Receiver operating characteristic curves for $E / A$ ratios. $P$ values for comparisons with no diagnostic vale (AUC $=0.5$, DeLong test); $A U C-$ area under the curve; $\mathrm{M}-$ month.

Table 4. Receiver operating curve analysis of $\mathrm{E} / \mathrm{A}$ and $\mathrm{E} / \mathrm{e}^{\prime}$ ratios as predictors of sinus rhythm maintenance 12 months after electrical cardioversion.

\begin{tabular}{lcccccc}
\hline Variable & AUC & Cutoff* $^{*}$ & Sensitivity (\%) & Specificity (\%) & PPV (\%) & NPV (\%) \\
\hline E/A & 0.726 & $\leq 2.2$ & 72.13 & 73.21 & 74.6 & 70.7 \\
E/e' & 0.726 & $\leq 9.17$ & 72.1 & 74.1 & 75.9 & 70.2 \\
\hline
\end{tabular}

*Cutoffs were calculated based on Youden's statistic; AUC — area under curve; NPV — negative predicting value; PPV — positive predicting value

In the current study, nearly all measures of LA size and systolic function and LV filling pressure were significant predictors of SR maintenance, this is in line with previous studies [2, 6-9, 12-19]. Importantly, it was found that echocardiographic measures of LV filling pressure were independent predictors of AF recurrence after electrical cardioversion. Similarly, several previous studies showed that $\mathrm{E} / \mathrm{e}^{\prime}$ ratios or $\mathrm{E} / \mathrm{A}$ ratios were independent predictors of $\mathrm{AF}$ recurrences after cardioversion or pulmonary vain isolation $[6,14,16,17]$. Although both $\mathrm{E} / \mathrm{e}$ ' and $\mathrm{E} / \mathrm{A}$ ratios are measures of $\mathrm{LV}$ filling pressure, $\mathrm{E} / \mathrm{A}$ values are more likely affected by loading status and thus depend on preload. In our study, E/A ratios predicted $\mathrm{AF}$ recurrence slightly better than $\mathrm{E} / \mathrm{e}$ ' (a higher odds ratio, but similar AUCs).
In the present study, patients regardless of LA size we included. Chung et al. [14] reported that $\mathrm{E} / \mathrm{e}$ ' ratios and LAVI were predictors of $\mathrm{AF}$ recurrence over 40 months in patients after pharmacological or electrical cardioversion, excluding patients with LA dimension > $50 \mathrm{~mm}$ [14]. Thus, $\mathrm{LV}$ filling pressure may be a predictor of AF even in patients with no visible structural remodeling. In the study by Chung et al. [14], an optimal E/e' cutoff for predicting AF recurrence (9.15) was very similar to that of the current study, with a similar sensitivity and specificity $(75 \%$ and $73.1 \%$, respectively). Those investigators did not analyse $\mathrm{E} / \mathrm{A}$ ratios.

In another study, among 127 patients with LA enlargement and LAVI $\geq 34 \mathrm{~mL} / \mathrm{m}^{2}$, AF recurred 
in $29 \%$ patients over 3 months [6]. In that study, septal E/e' ratios calculated during SR were the best predictor of $\mathrm{AF}$ recurrence after electrical cardioversion, with a cutoff $\geq 11$ better than $\geq 8$. In those patients with LA enlargement, LAVI was not a significant predictor of AF recurrence. Similarly, in another study, non-indexed LA volume and LA anteroposterior dimension did not differ between patients with maintenance of SR and AF recurrence [15].

Similar to our findings, Kosiuk et al. [17] showed that $\mathrm{E} / \mathrm{A}$ ratios were an independent risk factor for $\mathrm{AF}$ recurrence within 1 week after pulmonary vein isolation, but not 3-12 months after the procedure. Supposedly, E/A ratios can predict AF recurrence only shortly after pulmonary vein isolation because atrial haemodynamic function may be reduced transiently after this procedure.

Most studies on the predictors of SR maintenance after cardioversion have concentrated on LV and LA. However, Luong et al. [13] showed that the emptying fraction of RA predicted SR after electrical cardioversion better than did the emptying fraction of LA. Moreover, in another study, these investigators showed that RAVI was a better predictor of sinus rhythm maintenance after electrical cardioversion than LAVI [18]. In contrast, RA area was not a significant predictor of SR maintenance in our study.

Our study was carried out in one centre and involved a small sample. However, our study is one of the largest studies to date on echocardiographic predictors of SR maintenance after electrical cardioversion of $\mathrm{AF}$. When interpreting our results, one should remember that echocardiography is operator-dependent and requires experience and skill. Therefore, in our study, all echocardiographic measurements were taken by one experienced investigator. We carried out echocardiography after successful cardioversion during SR. Our current work is concentrated on finding echocardiographic predictors of SR maintenance that could be measured before cardioversion, i.e., during AF. In our study, we did not measure RA EF, which could be a predictor of SR maintenance after electrical cardioversion of AF. In this study, we did not analyse AF duration because we were not able to ascertain it reliably. AF is often asymptomatic or its symptoms can develop slowly [20, 21]. Many of our patients were unable tell when AF started. Lastly, heart rhythm monitoring was limited to a 24 -h Holter, at months 1 and 12, and a 12-lead electrocardiogram at the remaining follow-up visits.

\section{Conclusions}

Increased LV filling pressure assessed with $\mathrm{E} / \mathrm{A}$ and $\mathrm{E} / \mathrm{e}$ ' ratios may be an important risk factor for AF recurrence after successful electrical cardioversion. These findings are in line with previous research showing that increased filling pressure (septal E/e' ratios) is an independent predictor of mortality [19]. Our findings may help predict SR maintenance after electrical cardioversion, but further studies should investigate whether reducing $\mathrm{E} / \mathrm{A}$ or $\mathrm{E} / \mathrm{e}$ ' ratios could improve the outcomes of electrical cardioversions or ablation among patients with AF.

\section{Conflict of interest: None declared}

\section{References}

1. Magnani JW, Rienstra M, Lin H, et al. Atrial fibrillation: current knowledge and future directions in epidemiology and genomics. Circulation. 2011; 124(18): 1982-1993, doi: 10.1161/CIRCULATIONAHA.111.039677, indexed in Pubmed: 22042927.

2. Vizzardi E, Curnis A, Latini MG, et al. Risk factors for atrial fibrillation recurrence: a literature review. J Cardiovasc Med. 2014; 15(3): 235-253, doi: 10.2459/JCM.0b013e328358554b, indexed in Pubmed: 23114271.

3. Goette A, Kalman J, Aguinaga L, et al. EHRA/HRS/APHRS/ SOLAECE expert consensus on atrial cardiomyopathies: definition, characterization, and clinical implication. Europace. 2016; 18(10): 1455-1490, doi: 10.1093/europace/euw161.

4. Kirchhof P, Benussi S, Kotecha D, et al. 2016 ESC Guidelines for the management of atrial fibrillation developed in collaboration with EACTS. Europace. 2016; 18(11): 1609-1678, doi: 10.1093/ europace/euw295.

5. Pisters R, Nieuwlaat R, Prins MH, et al. Clinical correlates of immediate success and outcome at 1-year follow-up of realworld cardioversion of atrial fibrillation: the Euro Heart Survey. Europace. 2012; 14(5): 666-674, doi: 10.1093/europace/eur406.

6. Fornengo C, Antolini M, Frea S, et al. Prediction of atrial fibrillation recurrence after cardioversion in patients with left-atrial dilation. Eur Heart J Cardiovasc Imaging. 2015; 16(3): 335-341, doi: 10.1093/ehjci/jeu193, indexed in Pubmed: 25274966.

7. Wożakowska-Kapłon B, Bartkowiak R. Biomarkers for prognosis in atrial fibrillation: unfulfilled hopes. Pol Arch Med Wewn. 2015; 125(6): 400-401, indexed in Pubmed: 26134392.

8. Bartkowiak R, Wożakowska-Kapłon B, Janiszewska G. Plasma NT-proANP in patients with persistent atrial fibrillation who underwent successful cardioversion. Kardiol Pol. 2010; 68(1): 48-54, indexed in Pubmed: 20131188.

9. Wożakowska-Kaplon B, Bartkowiak R, Janiszewska G. A decrease in serum aldosterone level is associated with maintenance of sinus rhythm after successful cardioversion of atrial fibrillation. Pacing Clin Electrophysiol. 2010; 33(5): 561-565, doi: 10.1111/j.1540-8159.2009.02673.x, indexed in Pubmed: 20059712 . 
10. Lang R, Badano L, Mor-Avi V, et al. Recommendations for Cardiac Chamber Quantification by Echocardiography in Adults: An Update from the American Society of Echocardiography and the European Association of Cardiovascular Imaging. Eur Heart J Cardiovasc Imaging. 2015; 16(3): 233-271, doi: 10.1093/ehjci/jev014.

11. Nagueh SF, Smiseth OA, et al. Appleton CP Recommendations for the Evaluation of Left Ventricular Diastolic Function by Echocardiography: An Update from the American Society of Echocardiography and the European Association of Cardiovascular Imaging. Eur Heart J Cardiovasc Imaging. 2016; 17(12): 1321-1360.

12. Toufan M, Kazemi B, Molazadeh N. The significance of the left atrial volume index in prediction of atrial fibrillation recurrence after electrical cardioversion. J Cardiovasc Thorac Res. 2017; 9(1): 54-59, doi: 10.15171/jcvtr.2017.08, indexed in Pubmed: 28451089.

13. Luong CL, Thompson DJS, Gin KG, et al. Usefulness of the atrial emptying fraction to predict maintenance of sinus rhythm after direct current cardioversion for atrial fibrillation. Am J Cardiol. 2016; 118(9): 1345-1349, doi: 10.1016/j.amjcard.2016.07.066, indexed in Pubmed: 27658922.

14. Chung H, Lee BK, Min PKi, et al. Left ventricular filling pressure as assessed by the e/e' ratio is a determinant of atrial fibrillation recurrence after cardioversion. Yonsei Med J. 2016; 57(1): 64-71, doi: 10.3349/ymj.2016.57.1.64, indexed in Pubmed: 26632384 .

15. Wożakowska-Kapłon B, Opolski G. The dubious value of echocardiographic and plasma ANP measurements in predicting outcome of cardioversion in patients with persistent atrial fibrillation. Int J Cardiol. 2005; 103(3): 280-285, doi: 10.1016/j. ijcard.2004.08.062, indexed in Pubmed: 16098390.
16. Caputo M, Urselli R, Capati E, et al. Usefulness of left ventricular diastolic dysfunction assessed by pulsed tissue Doppler imaging as a predictor of atrial fibrillation recurrence after successful electrical cardioversion. Am J Cardiol. 2011; 108(5): 698-704, doi: 10.1016/j.amjcard.2011.04.018, indexed in Pubmed: 21723530 .

17. Kosiuk J, Breithardt OA, Bode K, et al. The predictive value of echocardiographic parameters associated with left ventricular diastolic dysfunction on short- and long-term outcomes of catheter ablation of atrial fibrillation. Europace. 2014; 16(8): 1168-1174, doi: 10.1093/europace/eut415, indexed in Pubmed: 24569573.

18. Luong C, Thompson DJS, Bennett M, et al. Right atrial volume is superior to left atrial volume for prediction of atrial fibrillation recurrence after direct current cardioversion. Can J Cardiol. 2015; 31(1): 29-35, doi: 10.1016/j.cjca.2014.10.009, indexed in Pubmed: 25547547.

19. Okura H, Takada Y, Kubo T, et al. Tissue Doppler-derived index of left ventricular filling pressure, E/E', predicts survival of patients with non-valvular atrial fibrillation. Heart. 2006; 92(9): 1248-1252, doi: 10.1136/hrt.2005.082594, indexed in Pubmed: 16449507.

20. Strickberger SA, Ip J, Saksena S, et al. Relationship between atrial tachyarrhythmias and symptoms. Heart Rhythm. 2005; 2(2): 125-131, doi: 10.1016/j.hrthm.2004.10.042, indexed in Pubmed: 15851283 .

21. Ziegler PD, Koehler JL, Mehra R. Comparison of continuous versus intermittent monitoring of atrial arrhythmias. Heart Rhythm. 2006; 3(12): 1445-1452, doi: 10.1016/j.hrthm.2006.07.030, indexed in Pubmed: 17161787. 